\title{
REFORMA DA PREVIDÊNCIA: UMA AVALIAÇÃO DOS IMPACTOS DISTRIBUTIVOS DA PROPOSTA DE EMENDA CONSTITUCIONAL 287/2016 SOBRE OS BENEFÍCIOS PROGRAMÁVEIS DE APOSENTADORIA DO RGPS
}

\author{
Luís Eduardo Afonso * \\ HÉlio ZYLBERSTAJN ${ }^{\dagger}$
}

\begin{abstract}
Resumo
Este artigo quantifica os aspectos distributivos da versão inicial da proposta de reforma da previdência apresentada no governo Temer. São calculadas a Taxa de Reposição, Taxa Interna de Retorno e Alíquota Necessária para os benefícios de Aposentadoria Por Tempo de Contribuição e Aposentadoria Por Idade do RGPS, para diferentes perfis de trabalhadores. Deixarão de existir diferenças por gênero, renda e benefício. Mulheres, aqueles(as) que se aposentam por idade e trabalhadores(as) de baixa renda serão mais afetados. A reforma não é neutra, nem mesmo durante o período de transição.
\end{abstract}

Palavras-chave: previdência social, reforma da previdência, PEC 287, RGPS, aspectos distributivos.

\begin{abstract}
This article quantifies the distributive aspects of the initial version of the pension reform proposal presented by the Temer government. We calculated the Replacement Rate, Internal Rate of Return and Required Rate for the Retirement by Contribution Time for the Retirement by Age benefits of RGPS for different profiles of workers. Differences by gender, income and benefit will no longer exist. Women, those who retire by age, and low-income workers are the most affected. The reform is not neutral, not even during the transition time.
\end{abstract}

Keywords: social security, pension reform, PEC 287, RGPS, distributive aspects.

JEL classification: H55, H53.

DOI: http://dx.doi .org/10.11606/1980-5330/ea 127338

\footnotetext{
* E-mail: lafonso@usp.br

† E-mail: hzylbers@usp.br
} 


\section{Introdução}

Em 06 de dezembro de 2016, o governo divulgou as medidas da Proposta de Emenda Constitucional (PEC) 287 (Presidência da República 2016). Esta é a proposição de reforma previdenciária, providência prometida desde que Michel Temer assumiu de forma definitiva a Presidência da República em agosto de 2016. A proposta é o mais abrangente e profundo conjunto de medidas da história recente da previdência social no Brasil. Baseia-se no diagnóstico de que o aumento das despesas dos Regimes Próprios de Previdência Social (RPPS) e do Regime Geral de Previdência Social (RGPS) fará com que os gastos previdenciários representem uma elevada e crescente proporção do dispêndio público, comprometendo a alocação de recursos públicos para todas as outras áreas. Adicionalmente, o déficit previdenciário tenderia a aumentar rapidamente, agravando este quadro e tornando seu financiamento insustentável em um período de tempo bastante curto.

Fica evidente que a motivação básica para a reforma foi o aspecto fiscal. A previsão do aumento explosivo de gastos com benefícios previdenciários coloca em risco as finanças públicas do país. Adicionalmente a aprovação da PEC 55 (a PEC do Teto dos Gastos), em dezembro de 2016, que limita em termos reais o dispêndio público, coloca uma limitação crível e reduz a possibilidade de expansão do dispêndio público, como vinha ocorrendo de forma quase ininterrupta desde a promulgação da Constituição de 1988. Desta maneira, a existência do teto imposto pela PEC 55 praticamente obriga que seja feita a reforma previdenciária, sob pena dos gastos com a previdência social tomarem todo o espaço do dispêndio público, situação obviamente insustentável e inconcebível. As alterações demográficas, com o acelerado envelhecimento populacional e o final do bônus demográfico não podem ser negligenciadas, como vem ocorrendo até agora.

Em que pese tal preocupação fiscal, há um aspecto igualmente importante, sobre o qual a literatura (Auerbach \& Lee 2011, Guillemard 1999) tem chamado a atenção: a questão da equidade. A versão original da PEC 287 definiu regras de aposentadoria comuns à maioria dos trabalhadores brasileiros, tanto para trabalhadores do setor público, quanto do setor privado. Este princípio de universalização é da maior relevância, na medida em que praticamente elimina o tratamento previdenciário desigual conforme a inserção no mercado de trabalho, prevalecente desde o início das instituições previdenciárias do Brasil. Desta forma, grosso modo, trabalhadores de uma mesma geração terão regras praticamente idênticas. Ou seja, os impactos intrageracionais no longo prazo não devem ser os mais importantes.

O mesmo não pode ser dito a respeito dos impactos que a proposta de reforma terá sobre gerações diferentes. O motivo é que o texto legal segregou os segurados em quatro grupos. O primeiro é formado pelos atuais aposentados e pensionistas. Como estes já usufruem do recebimento do benefício previdenciário, não serão afetados pela proposta. Continuarão recebendo os mesmos valores, sem qualquer alteração. O segundo grupo é composto pelos trabalhadores que já têm direito ao benefício, mas ainda não começaram a recebê-lo. Um exemplo é um trabalhador do setor privado, com 55 anos de idade e 35 anos de período contributivo, na data da promulgação da medida. Ele poderá se aposentar cumprindo apenas o requisito da regra anteriormente vigente (35 anos de contribuição). O terceiro grupo é formado pelos trabalhadores(as) que têm pelo menos 50 (45) anos de idade. Para estes, o período contributivo 
exigido antes da reforma será aumentado em $50 \%$, sendo o valor do benefício calculado de acordo com os termos da proposta de reforma. Finalmente, o quarto grupo tem como integrantes os indivíduos com idades inferiores a 50(45) anos. Para estes as regras da PEC 287 valerão integralmente.

Pelo exposto no parágrafo anterior, fica evidente que indivíduos de gerações, gêneros e condições de inserção distinta no mercado de trabalho serão afetados de maneira diferenciada pela proposição de reforma. Este fato, ao qual não tem sido dada a devida atenção, dará origem a impactos distributivos importantes. Estes são definidos nos moldes apresentados por Coronado et al. (2002) e mensurados, entre outros, por Forteza (2015), Gustman et al. (2012) e Schröder (2012). Esta é uma linha de pesquisa da maior relevância na área de previdência social. Com base neste quadro, este trabalho tem por objetivo a quantificação dos aspectos distributivos associados às medidas da PEC 287, por meio do cálculo de três indicadores de uso corrente na literatura previdenciária: Taxa de Reposição (TR), Taxa Interna de Retorno (TIR) e Alíquota Necessária (AliqNec). Os três indicadores são computados para os dois benefícios programáveis (portanto tipicamente previdenciários) mais importantes do RGPS: as aposentadorias por tempo de contribuição (ATC) e as aposentadorias por idade (AI).

Este texto está dividido em seis seções, incluindo esta introdução. A próxima seção traz as medidas mais importantes da PEC 287. A seção 3 apresenta o marco teórico e a literatura empírica sobre reformas previdenciárias. Na seção seguinte são reportados os procedimentos metodológicos do artigo. Na sequência, reportam-se os resultados e, encerrando, temos as conclusões do trabalho.

\section{A proposta de reforma do governo Temer: Elementos principais da PEC $287^{1}$.}

Esta Proposta de Emenda Constitucional é o mais expressivo conjunto de medidas de reforma da história recente da previdência no Brasil. Baseia-se em diagnóstico adequado do tipo e da magnitude dos problemas a serem enfrentados, em particular as diferentes regras e a insustentabilidade dos diferentes regimes. Por outro, alterações tão drásticas refletem a incapacidade da sociedade e de seus representantes no Executivo e no Legislativo implantarem anteriormente medidas mais graduais, em contexto econômico-demográfico mais favorável, de forma a minimizar os custos de transição e de adoção do conjunto de medidas, afetando um conjunto menor de indivíduos.

De maneira geral, a proposta de reforma apresentada pelo governo $\mathrm{Te}$ mer visa uniformizar as regras do RGPS e dos RPPS, especialmente quanto ao período contributivo, à idade para aposentadoria e sua forma de cálculo. O ponto central é o aumento do período contributivo, com a imposição de uma idade mínima única para aposentadoria. A seguir são apresentados os elementos mais importantes da proposição de reforma, particularmente no que se refere aos benefícios programáveis, ou seja, aposentadorias e pensões.

\footnotetext{
${ }^{1}$ Esta descrição da PEC 287 baseia-se fortemente na seção 5 de Turra \& Afonso (2017). Notese que este texto foi finalizado nos primeiros dias de fevereiro de 2017, antes que a PEC começasse a ser analisada pelo Legislativo. Desta forma, faz-se a ressalva que toda a argumentação aqui desenvolvida, bem como os cálculos feitos referem-se à versão original da PEC, tornada pública no início de dezembro de 2016
} 
O objetivo não é fazer uma análise de toda a proposta, mas sim apresentar os itens mais relevantes para a RGPS e para as diversas coortes afetadas pela mudança ${ }^{2}$.

\subsection{Condição de exigibilidade para aposentadoria e fórmula de cálculo do valor únicas para todos os trabalhadores}

Todos os servidores públicos vinculados aos RPPS e os trabalhadores do setor privado, de ambos os sexos, somente poderão se aposentar apenas aos 65 anos, com período contributivo mínimo de 25 anos. Para os trabalhadores vinculados ao RGPS, o valor do benefício passa a ser igual a $51 \%$ da média dos rendimentos de toda a vida ativa (limitados ao teto do salário-de-contribuição do RGPS), com um accrual rate de $1 \%$ por ano de contribuição. Assim, para um trabalhador que atingisse estritamente o requisito mínimo $(65 / 25)$ o valor da aposentadoria seria igual a $76 \%(51+25)$ do seu rendimento médio real. Para que pudesse obter uma Taxa de Reposição de 100\% (calculada com base em toda a vida ativa) teria que contribuir por 49 anos. Se houvesse iniciado seu período laboral (e contributivo) aos 18 anos, por exemplo, somente faria jus a um benefício equivalente à média dos seus salários de contribuição quando tivesse 67 anos de idade.

Como ocorre nesse tipo de reforma, aspecto da maior importância é a regra de transição para quem já se encontra no mercado de trabalho quando da aprovação da medida. Há regras diferenciadas para trabalhadores dos setores público e privado. Para os contribuintes do RGPS definiu-se um limite de 45 anos para as mulheres e 50 anos para os homens. Todos que forem mais jovens quando da promulgação da PEC deverão atender integralmente os requisitos de idade e de período contributivo. Já para aqueles com idade igual ou superior aos 50/45 anos, será exigido um adicional de 50\% do tempo necessário para completar o período contributivo. Por exemplo, um trabalhador com 53 anos de idade e 33 de contribuição esperaria contribuir mais dois anos para obter a aposentadoria por tempo de contribuição. Na forma definida na PEC, o tempo seria de três anos, aposentando-se aos 56 anos e não aos 55 como na regra antiga. Raciocínio análogo se aplica àqueles que iriam se aposentar por idade. Porém, neste caso vale a exigência de um período mínimo anterior à mudança de 15 anos de contribuição, aliado à idade mínima de 65 anos.

Para os servidores públicos, também há o limite de 45 anos para as mulheres e 50 anos para os homens, mas a transição é mais complexa, devido às regras adotadas quando da implantação das EC 20/1998, EC 41/2003 e $47 / 2005$. Além do acréscimo de $50 \%$, para os filiados aos RPPS, há requisitos quanto ao tempo no serviço público e ao cargo ocupado. Aqueles que ingressaram no setor público até 2003 têm direito à paridade e à integralidade. Para os que entraram a partir de 2004 e antes da implantação do regime de previdência complementar em seu ente, o benefício é calculado pela média dos maiores rendimentos, mas sem direito à paridade. Se o ente adotou um regime complementar, o valor do benefício está limitado ao teto do RGPS. Para os servidores com idade inferior aos mínimos (50 e 45 anos) valem as novas regras de cálculo de benefício (média aritmética e idade mínima).

\footnotetext{
${ }^{2} \mathrm{O}$ texto integral da PEC 287 pode ser encontrado em http://www.camara.gov.br/proposicoesWeb/prop_mostrarintegra;jsessionid=BF1C2D8C70F 9F690D956CBF2F1099980.proposicoesWebExterno1 ? codteor $=1514975 \&$ filename $=$ PEC $+287 /$ 2016
} 


\subsection{Aumento automático da idade de aposentadoria}

A idade mínima de aposentadoria aumentará um ano sempre que a expectativa de vida média no Brasil tiver um aumento de um ano inteiro. Desta forma, os 65 anos iniciais devem chegar a 68 anos em 2060. Este incremento recebe na literatura (Meneu et al. 2016) e (Vidal-Meliá et al. 2009) a denominação de Automatic Balancing Mechanism (ABM). O objetivo é criar um mecanismo de ajustamento automático entre receitas e despesas previdenciárias, de forma a evitar o elevado custo de renegociação do contrato previdenciário intergeracional, o que ocorre todas as vezes que os parâmetros do sistema se alteram de forma significativa. Na forma com que está sendo proposto, este mecanismo afeta somente os benefícios a serem concedidos no futuro. Desta maneira, funcionará, caso venha a ser implantado, como um substituto do Fator Previdenciário, que por sua vez afeta o valor dos novos benefícios.

\subsection{Regras mais restritivas para as pensões por morte}

Fica proibida a acumulação de pensões por morte e aposentadorias em qualquer dos regimes de previdência. A pensão passa a ser de $50 \%$ do benefício de aposentadoria que lhe deu origem, acrescido de $10 \%$ (não reversíveis) por dependente, até o limite de 100\% do teto. Ressalve-se que a Lei 13.135/2015 já havia definido que a duração das pensões seria condicional à idade do cônjuge. Esta lei poderia ter outra redação, pois faz referência à idade do cônjuge e não a sua expectativa de vida. Esta alteração funcionaria como um $A B M$ e estaria mais de acordo com o espírito da proposição de reforma feita pelo governo Temer.

\section{Marco teórico e literatura empírica}

\subsection{Marco teórico}

A fundamentação teórica para a análise das reformas é discutida na literatura sobre pension design. Em um nível mais geral, este termo está associado ao conjunto de decisões intertemporais consistentes entre si sobre benefícios ofertados (forma, elegibilidade, duração), sua forma de custeio e o ônus do seu financiamento, ou seja, são definições sobre o compartilhamento inter e intrageracional de riscos. Como apontam Pallares-Miralles et al. (2012) isto significa, inicialmente a elaboração da arquitetura geral, a definição dos parâmetros operacionais e avaliação do sistema previdenciário.

Estas escolhas devem ser consistentes com a conceituação dos sistemas previdenciários. Estes podem ser entendidos como um conjunto de arranjos destinados à reposição de renda durante a velhice (Feldstein \& Liebman 2002) e (Mattil 2006). Por este motivo são contratos sociais complexos, de gerenciamento dos riscos ligados à capacidade de geração de renda. Têm natureza intertemporal, mediados pelo governo, com diversas gerações sobrepostas e variadas dimensões de heterogeneidade.

Dada estas características, pode-se, conforme destacam (Barr \& Diamond 2006), apontar que todo sistema previdenciário tem ao menos quatro objetivos. O primeiro é funcionar como um mecanismo de provisão de renda no período de inatividade e desta forma permitir a suavização intertemporal do consumo. O segundo é atuar como um instrumento de redistribuição, que pode ser inter ou intrageracional. No primeiro caso, esta é a lógica inerente 
aos regimes de repartição, sendo as transferências realizadas entre indivíduos de gerações diferentes. No segundo caso, as transferências ocorrem entre indivíduos de uma mesma geração. O terceiro é operar como um mecanismo de seguro em relação aos riscos ligados à geração de renda e à longevidade. Finalmente, o quarto objetivo é permitir a redução da pobreza na velhice. Esta abordagem leva à conclusão que aos objetivos iniciais estão mais ligados os benefícios programáveis. Já os objetivos finais, estão relacionados de maneira mais próxima aos benefícios de risco e assistenciais. Como este trabalho tem como foco benefícios programáveis do RGPS (aposentadorias por tempo de contribuição e por idade) e às suas características distributivas, o procedimento empírico e os resultados obtidos estão mais explicitamente ligados aos objetivos iniciais dos sistemas previdenciários.

Uma vez apresentadas estas definições basilares, o passo seguinte é a definição de sete parâmetros operacionais do sistema (Pallares-Miralles et al. 2012), listados a seguir. Por definição, uma reforma paramétrica altera alguns destes parâmetros:

- Alíquotas de contribuição (incidência e valor);

- Condição de exigibilidade (vesting period);

- Fórmula de cálculo dos benefícios;

- Duração do pagamento dos benefícios;

- Forma de atualização dos rendimentos;

- Forma de correção dos benefícios;

- Delimitação de piso e teto;

- Means testing (pagamento de benefícios condicional à renda).

No caso particular da PEC 287 todas as mudanças contemplam o lado da despesa. Não há alterações no tocante às receitas do sistema. Logo, há basicamente modificações em apenas dois parâmetros no que se refere ao RGPS: a condição de exigibilidade (com a idade mínima de 65 anos e o período contributivo de 25 anos) e a fórmula de cálculo dos benefícios (deixando de existir o Fator Previdenciário e a Regra 85/95).

Concluindo, a etapa final preconizada pela literatura sobre pension design é avaliação do sistema de previdência (Merriam 1977). Esta pode ser entendida como a análise e quantificação da capacidade efetiva de um sistema previdenciário em prover os benefícios prometidos, de forma eficiente e segura, com distribuição adequada do ônus entre as diversas gerações. Segue-se aqui a abordagem de Favreault et al. (2012), que chamam a atenção para a necessidade de focar também nos aspectos distributivos inter e intrageracionais das reformas. Aqui, esta parte operacional é feita com o emprego de indivíduos representativos e com o cálculo dos indicadores previdenciários, apresentados na Seção 4. 


\subsection{Literatura empírica}

A literatura empírica sobre reformas previdenciárias tem se expandido, principalmente pelas alterações que vários países fizeram em seus sistemas previdenciários. Conforme a sistematização feita pela OECD (2015) todos os 34 países desta região fizeram algum tipo de reforma entre 2009 e 2013. Na América Latina, embora as reformas tivessem iniciado na década de 90, tiveram caráter mais estrutural, com a alteração de regimes de repartição para capitalização. Entretanto, tais reformas pouco alteraram os níveis de cobertura do sistema (OECD 2014).

Dentre os diversos países que fizeram reformas podem ser citados a Noruega (Hernæs et al. 2016); Peru (Olivera 2016); Bélgica (Devolder 2015), Nigéria e Tanzânia para os RPPS (Schwarz \& Abels 2016), Romênia e República Checa (Adascalitei \& Domonkos 2015). A heterogeneidade da relação dos países que reformaram seus sistemas é uma evidência de que o Brasil não está sozinho nesta difícil empreitada.

Há que se destacar três países de renda média que efetuaram reformas, que podem ser consideradas paradigmáticas para o Brasil. Os motivos são a similaridade do desequilíbrio fiscal originado do sistema previdenciário e a semelhança das medidas adotadas com aquelas que fazem parte da PEC 287. O primeiro é o caso da Hungria. Como requisito para obtenção de assistência financeira da União Europeia, foi abolido o pagamento da $13^{\mathrm{a}}$ parcela anual para novos beneficiários, congelou-se o piso previdenciário e elevou-se a idade mínima de aposentadoria de 62 para 65 anos, de 2016 a 2025. Também foram endurecidos os critérios para early retirement e para os benefícios de invalidez. Tais medidas somente foram implantadas de fato a partir de 2010, quando um governo conservador tomou posse, e conseguiu apoio do parlamento para levar a cabo as mudanças (Stepan \& Anderson 2014).

O segundo exemplo refere-se à Espanha. Conforme apresentam Díaz-Giménez \& Díaz-Saavedra (2016) o sistema deste país passou em curto espaço de tempo por duas alterações importantes. Em 2011, aprovou-se uma reforma paramétrica, que aumentou gradualmente a idade mínima de 65 para 67 anos, a idade do early retirement de 61 para 63 anos e elevou o número de anos empregado para calcular a aposentadoria. Em 2013, quando a reforma de dois anos antes estava começando a ser implantada, a idade do early retirement foi novamente elevada de 63 para 65 anos. Introduziu-se também um sustainability factor, que nos mesmos moldes do Fator Previdenciário, reduz o valor dos novos benefícios de acordo com a expectativa de vida. Adicionalmente introduziu-se o pension revaluation index, um ABM que reduz o valor de todas as aposentadorias para manter o equilíbrio atuarial do sistema, dada a previsão de receitas futuras. Como se pode notar, é uma reforma mais dura do que a proposta do governo brasileiro de 2016, pois ao contrário desta, a reforma espanhola afeta benefícios já concedidos.

O terceiro exemplo, ainda mais preocupantemente próximo do Brasil, é o caso da Grécia. Em 2010, pressionado por grave crise fiscal, o país empreendeu uma abrangente reforma previdenciária (Symeonidis 2016). A idade real de aposentadoria foi elevada de 62 para 65 anos para homens e mulheres, sendo este valor atrelado à expectativa de vida a partir de 2021. Os accrual rates, que variavam de 2 a 3\%, foram reduzidos para a faixa de $0,8 \%$ a 1,5\%. O período contributivo mínimo foi aumentado de 35 para 40 anos e a indexação dos benefícios não pode exceder o índice de preços ao consumidor. $\mathrm{O}$ 
período para o cálculo do benefício passou de 5 ou 10 anos, para toda a vida laboral. Os servidores públicos contratados a partir de 2010 ficaram sujeitos às mesmas regras dos trabalhadores do setor privado. Finalmente, definiu-se que até 2060 dispêndio previdenciário pode aumentar no máximo 2,5 pontos percentuais em relação ao PIB. Caso se verifiquem gastos superiores a este patamar, poderão ser feitas mudanças visando a estabilidade do sistema. Como se pode notar, há vários pontos de semelhança entre as reformas grega e brasileira, particularmente no que se refere ao aumento da idade mínima e à crise fiscal de ambos os países. Mas há duas diferenças principais: a reforma grega é mais abrangente; e mais importante, já foi implantada, enquanto a PEC 287 somente começou a ser debatida no congresso no início de 2017.

Fica claro que existe uma clara motivação fiscal para as reformas, provocada pelas mudanças demográficas que colocam, de forma bastante previsível, pressão sobre as contas públicas. Não se pode esquecer que há muitas dificuldades políticas para a implantação das reformas, mas também deve ser ressaltado que não se tem dado a devida atenção aos aspectos distributivos inerentes as estas reformas. É nesta lacuna que o presente artigo se insere.

\section{Metodologia}

\subsection{Indivíduos representativos}

Neste trabalho utiliza-se a metodologia dos indivíduos representativos. São construídos perfis hipotéticos de renda, aposentadoria e recebimento, conforme características observáveis relevantes para fins previdenciários. Conforme é tradição na literatura que emprega esta abordagem (Caetano 2006); Forteza e Ourens, 2009;(OECD 2015) todos os cálculos são feitos para diferentes combinações das seguintes variáveis:

- Gênero (homens e mulheres);

- Renda inicial (valores equivalentes a 1, 3 e 5 salários mínimos) ${ }^{3}$;

- Idade de entrada no mercado de trabalho (e de início das contribuições);

- Período contributivo;

- Idade de aposentadoria.

Uma vez definidos os perfis, constroem-se trajetórias intertemporais de renda. Com base nas regras e alíquotas de contribuição para trabalhadores assalariados do RGPS vigentes em janeiro de 2017 são calculadas as contribuições previdenciárias. O passo seguinte é o cálculo do benefício programável de aposentadoria, por tempo de contribuição e por idade. O período de recebimento do benefício é definido com base na Tábua de mortalidade para ambos os sexos 2015 do IBGE, a mesma empregada no cálculo do Fator Previdenciário. Com base nos fluxos de renda, contribuições e benefícios são calculados os indicadores apresentados na seção seguinte.

Esta escolha metodológica tem algumas vantagens: é uma técnica simples, não é necessário o emprego de dados reais e permitem-se várias dimensões de comparação, tanto entre indivíduos, quanto entre políticas públicas. Por

\footnotetext{
${ }^{3}$ No início de 2017 o salário mínimo tinha o valor de $\mathrm{R} \$ 937,00$.
} 
outro lado, é necessário fazer algumas hipóteses simplificadoras, como a densidade contributiva, a idade de entrada no mercado de trabalho e o período contributivo, que podem eventualmente afetar os resultados.

\subsection{Indicadores previdenciários}

Neste artigo são calculados três indicadores, de uso comum na literatura ${ }^{4}$. O primeiro é a Taxa de Reposição (TR). É igual à relação entre o primeiro benefício previdenciário $B_{i t}$, recebido pelo indivíduo i no instante t e sua última remuneração, no momento anterior à aposentadoria $W_{i t-1}$. Seu cálculo é apresentado na expressão (1). Quando adotados os valores brutos, este conceito é denominado TR bruta. Para o cálculo da TR líquida, devem ser usados os valores após a incidência dos tributos. Decidiu-se empregar a $T R$ bruta, por três motivos. O primeiro é a consistência com relação aos critérios adotados pelo IBGE em suas pesquisas. O segundo motivo é que o uso da TR bruta é mais adequado para a análise dos aspectos distributivos do RGPS e da reforma em curso. O terceiro motivo é a consistência com o uso consagrado da TR bruta na literatura.

$$
T R_{i}=\frac{B_{i t}}{W_{i t-1}}
$$

O uso da $T R$ tem aspectos positivos. O primeiro é a simplicidade. Pode-se calcular a $T R$ com apenas duas observações de duas variáveis, em períodos consecutivos. O segundo é a comparabilidade para sistemas previdenciários de países distintos. O terceiro aspecto é que para o cálculo da $T R$ não é necessário empregar uma taxa de desconto. O último ponto é a compreensibilidade. Por ser uma medida simples da variação da renda real quando da aposentadoria, pode ser facilmente interpretada.

Por outro lado, porém, a $T R$ é uma medida incompleta de características importantes de sistemas previdenciários. Como apontado por Biggs et al. (2009), a TR não permite nenhuma inferência sobre lifetime aspects, inerentes à lógica dos sistemas previdenciários. Este fato justifica o cálculo da Taxa Interna de Retorno (TIR), apresentada na expressão (2). O termo do lado esquerdo é VPC, valor presente das contribuições $C_{i t}$ descontadas à taxa TIR, da primeira à $N$-ésima contribuição. Para os benefícios $B_{i t}$, a explicação é análoga. A somatória tem início em $N+1$, quando ocorre o recebimento do primeiro benefício, até a idade terminal $\omega$. Este somatório é o Valor Presente dos Benefícios VPB. Por definição, a TIR é a taxa que iguala os fluxos dos dois lados da expressão.

$$
V P C_{i}=\sum_{t=1}^{N} \frac{C_{i t}}{(1+T I R)^{t}}=\sum_{t=N+1}^{\omega} \frac{B_{i t}}{(1+T I R)^{t}}=V P B_{i}
$$

A TIR também tem características que justificam seu uso. A primeira é que, assim como a $T R$, é uma variável que não é expressa em unidades monetárias, o que favorece a comparabilidade. A segunda é que TIR é calculada endogenamente. Desta maneira em seu cálculo não é necessária a escolha de uma taxa de desconto (que sempre pode trazer algum grau de discricionariedade), tendo em vista que esta é exatamente a definição da $T I R$.

\footnotetext{
${ }^{4}$ Esta subseção tem como referência básica a descrição feita na Seção 2.2 de Afonso (2016).
} 
O terceiro indicador é a Alíquota de Contribuição Necessária (AliqNec), apresentada na Equação (3). Representa qual deveria ser a alíquota de contribuição incidente sobre a renda, de tal forma que o valor presente esperado dos benefícios $V P B$ seja igual ao valor presente esperado da renda $V P R$ para cada indivíduo $i$ que faz parte do sistema. Isto pode ser facilmente visto, multiplicando o denominador da Equação (3) (igual ao Valor Presente da Renda $V P R$ ) por AliqNec, o que gera o Valor Presente das Contribuições VPC. Para o cálculo de AliqNec é necessário o emprego de uma taxa de desconto $r$, cujo valor não é consensual na literatura, como apontam Boado-Penas et al. (2008). Este indicador é importante, pois assim como a $T I R$, tem caráter intertemporal e também por representar uma medida de quanto a alíquota cobrada está distante da alíquota teórica que equilibraria atuarialmente os fluxos para o segurado.

$$
\text { AliqNec }_{i}=\frac{\sum_{t=N+1}^{\omega} \frac{B_{i t}}{(1+r)^{t}}}{\sum_{t=1}^{N} \frac{R_{i t}}{(1+r)^{t}}}=\frac{V P B_{i}}{V P R_{i}}
$$

\section{Resultados}

Nesta seção são apresentados os resultados dos três indicadores apresentados na seção anterior, para três situações. O primeiro conjunto refere-se às regras vigentes para os trabalhadores antes da PEC 287. Neste grupo estão incluídos todos os que já completaram os requisitos mínimos para se aposentar, de acordo com a regras pré-PEC. O segundo conjunto refere-se a todos os trabalhadores que se aposentarão com as novas regras. Enquadram-se aqui todos os homens (mulheres) com menos de 50(45) anos. O terceiro conjunto, mais complexo, trata dos trabalhadores que com mais de 50(45) anos, que deverão cumprir um período contributivo adicional de 50\% para completarem o requisito contributivo, conforme definido na regra de transição. Além dos três indicadores selecionados (TR, TIR e AliqNec) são também apresentados os valores dos benefícios de aposentadoria para cada situação analisada.

\subsection{A situação anterior à PEC 287}

Nesta seção os resultados estão divididos em dois subgrupos. O primeiro refere-se às condições de obtenção do benefício de aposentadoria por tempo de contribuição com a incidência do Fator Previdenciário, válidas desde a criação deste soft $A B M$ em 1999. Estes resultados são apresentados na Tabela 1. Na sequência são relatados na Tabela 2 os valores obtidos com as condições prevalecentes após a entrada em vigor da Regra 85/95 progressiva, definidas pela Lei 13.183/2015. Este ato legal definiu que sempre que a soma do período contributivo com a idade somar determinado valor, inicialmente 85 para as mulheres e 95 para os homens, a incidência do Fator Previdenciário será opcional. Embora as condições da Regra 85 prevaleçam, sob o ponto de vista do segurado (porque o benefício nunca será inferior ao obtido com o Fator Previdenciário) optou-se por apresentar ambos os impactos, para que se possa comparar o efeito da adoção da Regra 85/95. Fica claro que esta foi uma medida de cunho populista, tomada sem as devidas avaliações, na contramão dos esforços de contração das despesas e que vai contra o equacionamento das contas previdenciárias. 
Os valores das duas tabelas foram obtidos para períodos contributivos de 25 a 49 anos, para que possam ser comparados com as condições impostas pela proposta do governo Temer. Os 25 anos são o período contributivo mínimo para obtenção do benefício, conforme proposto pela proposta de reforma; os 49 anos são o número de anos para que seja obtido o benefício integral ${ }^{5}$. Os valores foram calculados supondo que os trabalhadores entram no mercado de trabalho com a idade mínima de 16 anos e têm densidade contributiva de $100 \%$, ou seja, que contribuem por toda a vida ativa. Note-se que esta é uma hipótese simplificadora que tende a subestimar o período laboral para que se complete o período contributivo de 25 anos, particularmente para trabalhadores de baixa renda. Em todos os casos adotou-se uma taxa de crescimento da renda de $2 \%$ ao ano, conforme estimado por Giambiagi \& Afonso (2009) e Afonso (2016). De forma consistente com essa premissa, adotou-se uma taxa de desconto de $2 \%$ para o cálculo de AliqNec.

Tabela 1: Indicadores previdenciários - Situação Atual - ATC - Fator Previdenciário

\begin{tabular}{|c|c|c|c|c|c|c|c|c|c|}
\hline \multirow{2}{*}{$\begin{array}{c}\text { TC } \\
\text { (anos) }\end{array}$} & \multirow[b]{2}{*}{$\begin{array}{c}\text { Renda } \\
\text { inicial (SM) }\end{array}$} & \multicolumn{4}{|c|}{ Homens } & \multicolumn{4}{|c|}{ Mulheres } \\
\hline & & $\begin{array}{l}\text { TR } \\
(\%)\end{array}$ & $\begin{array}{l}\text { TIR } \\
(\%)\end{array}$ & $\begin{array}{c}\text { AliqNec } \\
(\%)\end{array}$ & $\begin{array}{l}\text { Valor } \\
\text { (R\$) }\end{array}$ & $\begin{array}{l}\text { TR } \\
(\%)\end{array}$ & $\begin{array}{l}\text { TIR } \\
(\%)\end{array}$ & $\begin{array}{c}\text { AliqNec } \\
(\%)\end{array}$ & $\begin{array}{l}\text { Valor } \\
\text { (R\$) }\end{array}$ \\
\hline \multirow{3}{*}{25} & 1 & 63,42 & 5,13 & 65,75 & 937 & 63,42 & 5,13 & 65,75 & 937 \\
\hline & 3 & 24,24 & 1,27 & 25,13 & 1074 & 29,39 & 1,94 & 30,47 & 1303 \\
\hline & 5 & 21,40 & 0,97 & 22,19 & 1581 & 25,94 & 1,63 & 26,90 & 1917 \\
\hline \multirow{3}{*}{30} & 1 & 57,44 & 3,70 & 45,98 & 937 & 57,44 & 3,70 & 45,98 & 937 \\
\hline & 3 & 33,42 & 1,50 & 26,75 & 1635 & 39,38 & 2,06 & 31,52 & 1927 \\
\hline & 5 & 27,84 & 1,06 & 22,29 & 2271 & 32,80 & 1,60 & 26,26 & 2675 \\
\hline \multirow{3}{*}{35} & 1 & 52,02 & 2,41 & 31,83 & 937 & 52,11 & 2,41 & 31,89 & 939 \\
\hline & 3 & 45,17 & 1,62 & 27,64 & 2440 & 52,11 & 2,09 & 31,89 & 2816 \\
\hline & 5 & 35,42 & 1,02 & 21,67 & 3190 & 40,86 & 1,49 & 25,00 & 3680 \\
\hline \multirow{3}{*}{40} & 1 & 60,49 & 2,08 & 28,95 & 1203 & 68,68 & 2,49 & 32,86 & 1366 \\
\hline & 3 & 60,04 & 1,76 & 28,73 & 3582 & 68,16 & 2,17 & 32,62 & 4066 \\
\hline & 5 & 44,58 & 1,04 & 21,33 & 4432 & 50,61 & 1,44 & 24,22 & 5032 \\
\hline \multirow{3}{*}{45} & 1 & 80,97 & 2,18 & 30,01 & 1778 & 90,76 & 2,54 & 33,64 & 1993 \\
\hline & 3 & 78,53 & 1,83 & 29,10 & 5173 & 83,98 & 2,04 & 31,12 & 5531 \\
\hline & 5 & 50,39 & 0,68 & 18,67 & 5531 & 50,39 & 0,68 & 18,67 & 5531 \\
\hline \multirow{3}{*}{49} & 1 & 102,87 & 2,26 & 30,86 & 2445 & 114,34 & 2,58 & 34,30 & 2717 \\
\hline & 3 & 77,58 & 1,15 & 23,27 & 5531 & 77,58 & 1,15 & 23,27 & 5531 \\
\hline & 5 & 46,55 & $-0,21$ & 13,96 & 5531 & 63,42 & 5,13 & 13,96 & 5531 \\
\hline
\end{tabular}

As Tabelas 1 e 2 revelam a existência de alguns padrões de resultados. Quando a renda inicial é de 1 salário mínimo (SM), e o período contributivo é reduzido, o valor do benefício é igual a R\$ 937 (1 SM). Isso ocorre porque a aplicação do Fator Previdenciário bastante inferior a 1, dada a idade de aposentadoria baixa faria com que o valor do benefício fosse inferior ao piso de 1 SM. Como a legislação impede que isso aconteça, a aposentadoria é majorada para o piso. Como resultado, os demais indicadores são igualmente afetados, com aumentos da $T I R$, da $T R$ e da AliqNec. Na situação oposta, a combinação de períodos contributivos maiores e renda inicial elevada faz com que o

\footnotetext{
${ }^{5} \mathrm{O}$ termo integral é um tanto quanto impreciso. No contexto empregado, significa que o benefício é igual à média dos salários de contribuição de toda a vida ativa do trabalhador. Deve ser enfatizado que não significa que a aposentadoria é igual ao valor da última renda antes da aposentadoria.
} 
teto do salário de contribuição seja alcançado rapidamente e o Fator Previdenciário tenha valor superior a 1 . Neste caso o benefício seria superior ao teto, o que também não pode ocorrer. Assim, ao ter seu valor reduzido para o limite superior, os demais indicadores são igualmente diminuídos. Fica claro que a existência do piso e do teto previdenciário tem importantes impactos distributivos, pois aumentam (diminuem) todos os indicadores para as faixas de renda mais baixas (altas), bem como para períodos contributivos menores (maiores). Esta característica repete-se para vários resultados e encontra-se em consonância com o apontado por Lindbeck (2006).

Em seu conjunto estes elementos contribuem para que as ATCs do RGPS apresentem progressividade, verificada em todos os indicadores calculados. Em todas as situações as mulheres têm indicadores mais favoráveis que os homens. Em boa parte esta diferença é explicada pela fórmula de cálculo do Fator Previdenciário, que dá a elas cinco anos adicionais no tempo de contribuição. Em boa parte esta diferença é explicada pelo fato de as mulheres poderem se aposentar cinco anos antes dos homens e pelo uso da tábua de mortalidade de ambos os sexos no cálculo do Fator Previdenciário, o que é um tipo de subsídio implícito, visto que a expectativa de sobrevida feminina é maior para todas as idades.

Cabe, no entanto, uma cuidadosa e mandatória ressalva. A característica redistributiva deste benefício programável e contributivo tem um custo para a sociedade, que constitui a outra face do déficit previdenciário, pois, em boa parte, estes resultados para os indicadores são incompatíveis com a capacidade de geração de renda e de contribuição da sociedade. Este argumento é exemplificado pelos resultados encontrados para o primeiro período contributivo normal: 30 anos para as mulheres e 35 anos para os homens. Neste caso as taxas de reposição são relativamente baixas, mas compatíveis com a experiência internacional (OECD 2015, Purcell 2012). Para o caso masculino, com exceção da faixa de renda mais elevada, as alíquotas necessárias são próximas do valor legal (28-31\%). Como o valor calculado refere-se ao custeio de somente um benefício (ATC), fica evidente que o RGPS não pode ter equilíbrio entre receitas e despesas. Para as mulheres que se aposentam com 30 anos de contribuição, o desequilíbrio é ainda mais evidente. Particularmente para aquelas cujo benefício é igual ao piso, a alíquota necessária deveria ser próxima de $46 \%$.

A Tabela 2 apresenta os valores obtidos com a vigência da Regra 85/95 progressiva. Esta medida implicou benefícios mais altos (comparativamente à regra do Fator) para alguns grupos de trabalhadores, notadamente os homens e mulheres com 40 anos de período de contributivo e os as mulheres com 35 anos de contribuição (células em cinza na tabela). Tipicamente estes ganhos ocorrem quando duas condições são verificadas simultaneamente: a Regra 85/95 é atingida e o Fator Previdenciário é menor do que 1. A inadequação desta regra fica óbvia quando se nota que os homens que se beneficiaram com a mudança terão acréscimo de mais de 20 pontos percentuais em suas TRs (o que gera uma alíquota necessária quase 21 pontos percentuais superior). Para as mulheres com 35 anos de contribuição, o ganho na $T R$ é da ordem de 45 pontos percentuais, o que gera incremento da mesma magnitude na alíquota necessária. Para as mulheres com período contributivo de 40 anos, o incremento é menor, ao redor de 6,5 pontos percentuais para a $T R$. Uma medida como essa é questionável, por permitir ganhos tão grandes, em um cenário econômico-demográfico tão adverso. E os danos pela implantação da 
Regra 85/95 podem ser ainda mais elevados, pois certamente vários trabalhadores postergaram sua aposentadoria, com base nestas novas condições. Tais conclusões, de certa forma já haviam sido antecipadas por Penafieri \& Afonso (2013), que trataram da possibilidade de adoção de medidas desta natureza no RGPS. Fica evidente que tal regra não é atuarialmente justa ou neutra, nos termos de Queisser, Monika and Whitehouse, Edward R and others (2006).

Tabela 2: Indicadores previdenciários - Situação Atual - Regra 85/95

\begin{tabular}{|c|c|c|c|c|c|c|c|c|c|}
\hline \multirow{2}{*}{$\begin{array}{c}\text { TC } \\
\text { (anos) }\end{array}$} & \multirow{2}{*}{$\begin{array}{c}\text { Renda } \\
\text { inicial (SM) }\end{array}$} & \multicolumn{4}{|c|}{ Homens } & \multicolumn{4}{|c|}{ Mulheres } \\
\hline & & $\begin{array}{l}\text { TR } \\
(\%)\end{array}$ & $\begin{array}{l}\text { TIR } \\
(\%)\end{array}$ & $\begin{array}{c}\text { AliqNec } \\
(\%)\end{array}$ & $\begin{array}{l}\text { Valor } \\
\text { (R\$) }\end{array}$ & $\begin{array}{l}\text { TR } \\
(\%)\end{array}$ & $\begin{array}{l}\text { TIR } \\
(\%)\end{array}$ & $\begin{array}{c}\text { AliqNec } \\
(\%)\end{array}$ & $\begin{array}{l}\text { Valor } \\
\text { (R\$) }\end{array}$ \\
\hline \multirow{3}{*}{25} & 1 & 63,42 & 5,13 & 65,75 & 937 & 63,42 & 5,13 & 65,75 & 937 \\
\hline & 3 & 24,24 & 1,27 & 25,13 & 1074 & 29,39 & 1,94 & 30,47 & 1303 \\
\hline & 5 & 21,40 & 0,97 & 22,19 & 1581 & 25,94 & 1,63 & 26,90 & 1917 \\
\hline \multirow{3}{*}{30} & 1 & 57,44 & 3,70 & 45,98 & 937 & 57,44 & 3,70 & 45,98 & 937 \\
\hline & 3 & 33,42 & 1,50 & 26,75 & 1635 & 39,38 & 2,06 & 31,52 & 1927 \\
\hline & 5 & 27,84 & 1,06 & 22,29 & 2271 & 32,80 & 1,60 & 26,26 & 2675 \\
\hline \multirow{3}{*}{35} & 1 & 52,02 & 2,41 & 31,83 & 937 & 75,43 & 3,65 & 46,16 & 1359 \\
\hline & 3 & 45,17 & 1,62 & 27,64 & 2440 & 75,43 & 3,33 & 46,16 & 4076 \\
\hline & 5 & 35,42 & 1,02 & 21,67 & 3190 & 59,15 & 2,70 & 36,19 & 5327 \\
\hline \multirow{3}{*}{40} & 1 & 73,11 & 2,69 & 34,99 & 1454 & 73,11 & 2,69 & 34,99 & 1454 \\
\hline & 3 & 72,57 & 2,37 & 34,72 & 4329 & 72,57 & 2,37 & 34,72 & 4329 \\
\hline & 5 & 53,88 & 1,64 & 25,78 & 5357 & 53,88 & 1,64 & 25,78 & 5357 \\
\hline \multirow{3}{*}{45} & 1 & 80,97 & 2,18 & 30,01 & 1778 & 90,76 & 2,54 & 33,64 & 1993 \\
\hline & 3 & 78,53 & 1,83 & 29,10 & 5173 & 83,98 & 2,04 & 31,12 & 5531 \\
\hline & 5 & 50,39 & 0,68 & 18,67 & 5531 & 50,39 & 0,68 & 18,67 & 5531 \\
\hline \multirow{3}{*}{49} & 1 & 102,87 & 2,26 & 30,86 & 2445 & 114,34 & 2,58 & 34,30 & 2717 \\
\hline & 3 & 77,58 & 1,15 & 23,27 & 5531 & 77,58 & 1,15 & 23,27 & 5531 \\
\hline & 5 & 46,55 & $-0,21$ & 13,96 & 5531 & 46,55 & $-0,21$ & 13,96 & 5531 \\
\hline
\end{tabular}

Nas Tabelas 3 e 4 são apresentados os indicadores referentes à aposentadoria por idade. Os valores foram obtidos para as idades mínimas (65 anos para homens e 60 para mulheres) e diferentes idades de início de contribuição e períodos de contribuição. Por exemplo, a primeira linha da Tabela 3 traz o caso de um homem que iniciou seu período contributivo aos 50 anos, tendo contribuído sem interrupções por 15 anos, e assim sucessivamente nas linhas seguintes, reduzindo a idade inicial e aumentando o número de anos de contribuições.

Todos os indicadores são bem mais elevados para as AI do que para as ATC. Ou seja, o sistema é redistributivo, pois os indivíduos que se aposentam por idade têm renda mais baixa e menor escolaridade do que os que obtêm a ATC (Afonso 2016). Como as taxas de reposição são muito elevadas, a alíquota necessária também é extremamente alta, em um patamar inconsistente com o equilíbrio atuarial. Por outro lado, como as aposentadorias são concedidas a idades mais altas que as ATCs, o menor tempo de recebimento do benefício faz com que a TIR não seja tão alta para os homens (com exceção dos grupos iniciais). Já para as mulheres, os indicadores são mais expressivos. Ou seja, as AI são ainda mais redistributivas que as ATC. Porém, como já apontado, este subsídio gera desequilíbrio nas contas do RGPS. Estes resultados sinalizam forte evidência de que grupos diferentes serão afetados de forma distinta pela PEC 287, tanto na transição, quanto no período de vigência plena das regras. Este fato merece ser tratado com cuidado, conforme apontado por Schmähl (1999). 
Tabela 3: Indicadores previdenciários - Situação Atual - AI - Homens

\begin{tabular}{|c|c|c|c|c|c|}
\hline $\begin{array}{c}\text { TC (anos) } \\
\text { Idade inicial }\end{array}$ & $\begin{array}{c}\text { Renda } \\
\text { inicial (SM) }\end{array}$ & $\begin{array}{l}\text { TR } \\
(\%)\end{array}$ & $\begin{array}{l}\text { TIR } \\
(\%)\end{array}$ & $\begin{array}{c}\text { AliqNec } \\
(\%)\end{array}$ & $\begin{array}{l}\text { Valor } \\
(\mathrm{R} \$)\end{array}$ \\
\hline \multirow{2}{*}{15} & 1 & 77,30 & 8,66 & 75,70 & 937 \\
\hline & 3 & 70,71 & 7,34 & 69,29 & 2571 \\
\hline 50 & 5 & 68,98 & 7,21 & 67,59 & 4181 \\
\hline \multirow{2}{*}{20} & 1 & $\overline{73,72}$ & 5,69 & 54,18 & 937 \\
\hline & 3 & 73,72 & 5,11 & 54,18 & 2960 \\
\hline 45 & 5 & 68,68 & 4,81 & 50,48 & 4596 \\
\hline \multirow{2}{*}{25} & 1 & 75,96 & 4,27 & 44,66 & 1122 \\
\hline & 3 & 75,96 & 3,77 & 44,66 & 3367 \\
\hline 40 & 5 & 67,05 & 3,32 & 39,42 & 4954 \\
\hline \multirow{2}{*}{30} & 1 & 77,74 & 3,32 & 38,09 & 1268 \\
\hline & 3 & 77,74 & 2,89 & 38,09 & 3805 \\
\hline 35 & 5 & 64,76 & 2,30 & 31,73 & 5282 \\
\hline \multirow[b]{2}{*}{35} & 1 & 78,22 & 2,60 & 32,85 & 1409 \\
\hline & 3 & 78,22 & 2,23 & 32,85 & 4227 \\
\hline 30 & 5 & 61,34 & 1,51 & 25,76 & 5524 \\
\hline \multirow{2}{*}{40} & 1 & 87,41 & 2,46 & 32,12 & 1738 \\
\hline & 3 & 86,76 & 2,11 & 47,01 & 5176 \\
\hline 25 & 5 & 55,63 & 0,78 & 20,44 & 5531 \\
\hline \multirow{2}{*}{45} & 1 & 96,10 & 2,33 & 31,39 & 2110 \\
\hline & 3 & 83,98 & 1,62 & 27,43 & 5531 \\
\hline 20 & 5 & 50,39 & 0,19 & 16,46 & 5531 \\
\hline \multirow{2}{*}{49} & 1 & 102,87 & 2,26 & 30,86 & 2445 \\
\hline & 3 & 77,58 & 1,15 & 23,27 & 5531 \\
\hline 16 & 5 & 46,55 & $-0,21$ & 13,96 & 5531 \\
\hline
\end{tabular}

\subsection{A proposta do governo Temer - Qual o impacto sobre os indicadores?}

Esta proposição de reforma, caso venha a ser aprovada em sua totalidade, torna as regras da previdência mais simples e praticamente eliminará as diferenças entre os trabalhadores dos setores público e privado. Com as mudanças, a condição de exigibilidade para aposentadoria passa a ser 65 anos de idade e 25 anos de contribuição, sem diferenciação por gênero. As duas espécies de benefícios programáveis existentes (aposentadoria por tempo de contribuição e por idade) deixam de existir, passando a haver somente um tipo de aposentadoria.

A Tabela 5 apresenta os indicadores para diferentes combinações de período contributivo e idade inicial de contribuição. Note-se que os valores são válidos para homens e mulheres, dado que deixará de existir a diferença de gêneros. Os valores apresentados devem ser comparados com aqueles reportados nas Tabelas 1 a 4 . O primeiro ponto a ser destacado é uma queda geral em todos os indicadores, o que evidencia o rigor da reforma proposta. Note-se que com a nova regra, há pouca diferenciação nas Taxas de Reposição (pouco superiores a $60 \%$ em média) quando se aumenta o período contributivo, diferentemente do que ocorre hoje com as ATC pelo Fator Previdenciário, ou pela Regra 85/95. A progressividade no tocante à renda também é bastante redu- 
Tabela 4: Indicadores previdenciários - Situação Atual - AI Mulheres

\begin{tabular}{|c|c|c|c|c|c|}
\hline $\begin{array}{c}\text { TC (anos) } \\
\text { Idade inicial }\end{array}$ & $\begin{array}{c}\text { Renda } \\
\text { inicial (SM) }\end{array}$ & $\begin{array}{l}\text { TR } \\
(\%)\end{array}$ & $\begin{array}{l}\text { TIR } \\
(\%)\end{array}$ & $\begin{array}{c}\text { AliqNec } \\
(\%)\end{array}$ & $\begin{array}{l}\text { Valor } \\
\text { (R\$) }\end{array}$ \\
\hline \multirow{2}{*}{15} & 1 & 77,30 & 9,18 & 89,22 & 937 \\
\hline & 3 & 70,71 & 7,93 & 81,61 & 2571 \\
\hline 45 & 5 & 68,98 & 7,81 & 79,61 & 4181 \\
\hline \multirow{2}{*}{20} & 1 & $\overline{73,72}$ & 6,27 & 63,81 & 937 \\
\hline & 3 & 73,72 & 5,73 & 63,81 & 2960 \\
\hline 40 & 5 & 68,68 & 5,44 & 59,45 & 4596 \\
\hline \multirow{2}{*}{25} & 1 & 75,96 & 4,85 & 52,60 & 1122 \\
\hline & 3 & 75,96 & 4,39 & 52,60 & 3367 \\
\hline 35 & 5 & 67,05 & 3,95 & 46,43 & 4954 \\
\hline \multirow{2}{*}{30} & 1 & 77,74 & 3,90 & 44,86 & 1268 \\
\hline & 3 & 77,74 & 3,49 & 44,86 & 3805 \\
\hline 30 & 5 & 64,76 & 2,93 & 37,37 & 5282 \\
\hline \multirow[b]{2}{*}{35} & 1 & 75,43 & 3,03 & 37,31 & 1359 \\
\hline & 3 & 75,43 & 2,68 & 37,31 & 4076 \\
\hline 25 & 5 & 59,15 & 2,01 & 29,26 & 5327 \\
\hline \multirow{2}{*}{40} & 1 & 80,24 & 2,69 & 34,73 & 1596 \\
\hline & 3 & 79,64 & 2,36 & 34,47 & 4751 \\
\hline 20 & 5 & 55,63 & 1,40 & 24,08 & 5531 \\
\hline \multirow{2}{*}{44} & 1 & 85,93 & 2,56 & 33,81 & 1850 \\
\hline & 3 & 83,80 & 2,21 & 32,97 & 5411 \\
\hline 16 & 5 & 51,39 & 0,92 & 20,22 & 5531 \\
\hline
\end{tabular}

zida. Essas duas características, aliadas ao fim da diferenciação por gênero, permitem afirmar que a reforma proposta reduzirá sobremaneira as características distributivas do sistema previdenciário. Ressalte-se que as mulheres serão as mais afetadas, tendo em vista que todos os seus indicadores são, com a situação anterior à PEC 287, mais elevados que os dos homens. Estas conclusões encontram paralelo na discussão apresentada por Breyer \& Hupfeld (2010) para o caso da Alemanha.

Estes resultados podem ser mais bem compreendidos se forem analisados de forma comparativa. A Tabela 6 apresenta os resultados dos indicadores selecionados na melhor situação pré-reforma para os trabalhadores, a Regra 85/95. Calculou-se o que teria acontecido se estes tivessem atendido as condições de idade contributiva inicial e período contributivo dadas pela Tabela 5, mas houvessem se aposentado com a fórmula de cálculo dada pela Regra 85/95. Desta forma, pode-se isolar o efeito da fórmula de cálculo do benefício da PEC 287.

Os dados das Tabelas 5 e 6 permitem duas conclusões principais. A primeira é que, dados os mesmos períodos contributivos (TC) e idade inicial, a regra da PEC 287 afeta muito mais os indivíduos com períodos contributivos maiores. Aqueles que iniciaram sua contribuição mais tardiamente e mantiveram-se como contribuintes (ou que eventualmente têm períodos contributivos mais espaçados), serão menos afetados. A segunda conclusão, em consonância com os argumentos previamente apresentados, é que a PEC afeta muito mais as mulheres do que os homens. É notável a redução verificada nos indicadores. Também é importante comparar os resultados para o maior 
Tabela 5: Indicadores previdenciários - PEC 287 - Homens e mulheres

\begin{tabular}{|c|c|c|c|c|c|}
\hline \multirow{2}{*}{$\frac{\mathrm{TC} \text { (anos) }}{\text { Idade inicial }}$} & \multirow[b]{2}{*}{$\begin{array}{c}\text { Renda } \\
\text { inicial (SM) }\end{array}$} & \multicolumn{4}{|c|}{ Homens e Mulheres } \\
\hline & & $\begin{array}{l}\text { TR } \\
(\%)\end{array}$ & $\begin{array}{l}\text { TIR } \\
(\%)\end{array}$ & $\begin{array}{c}\text { AliqNec } \\
(\%)\end{array}$ & $\begin{array}{l}\text { Valor } \\
\text { (R\$) }\end{array}$ \\
\hline 25 & 1 & 62,17 & 3,39 & 37,28 & 937 \\
\hline \multirow[b]{2}{*}{40} & 3 & 60,54 & 2,77 & 36,30 & 2737 \\
\hline & 5 & 54,14 & 2,38 & 32,47 & 4080 \\
\hline 30 & 1 & 61,68 & 2,41 & 30,82 & 1026 \\
\hline \multirow{2}{*}{35} & 3 & 61,68 & 1,98 & 30,82 & 3079 \\
\hline & 5 & 52,53 & 1,49 & 26,25 & 4370 \\
\hline 35 & 1 & 62,65 & 1,81 & 26,84 & 1151 \\
\hline \multirow{2}{*}{30} & 3 & 62,65 & 1,43 & 26,84 & 3453 \\
\hline & 5 & 50,69 & 0,85 & 21,71 & 4657 \\
\hline 40 & 1 & 63,48 & 1,37 & 23,79 & 1288 \\
\hline \multirow{2}{*}{25} & 3 & 62,88 & 1,01 & 23,57 & 3826 \\
\hline & 5 & 48,72 & 0,37 & 18,26 & 4941 \\
\hline 45 & 1 & 64,17 & 1,05 & 21,38 & 1437 \\
\hline \multirow{2}{*}{20} & 3 & 62,19 & 0,67 & 20,72 & 4178 \\
\hline & 5 & 46,64 & $-0,01$ & 15,54 & 5223 \\
\hline 49 & 1 & 64,64 & 0,84 & 19,78 & 1567 \\
\hline \multirow{2}{*}{16} & 3 & 61,17 & 0,44 & 18,72 & 4448 \\
\hline & 5 & 44,95 & $-0,26$ & 13,75 & 5448 \\
\hline
\end{tabular}

Tabela 6: Indicadores previdenciários - Regra 85/95 com requisitos da PEC 287

\begin{tabular}{|c|c|c|c|c|c|c|c|c|c|}
\hline \multirow{2}{*}{$\begin{array}{c}\text { TC } \\
\text { (anos) } \\
\text { Idade } \\
\text { inicial }\end{array}$} & \multirow{2}{*}{$\begin{array}{c}\text { Renda } \\
\text { inicial (SM) }\end{array}$} & \multicolumn{4}{|c|}{ Homens } & \multicolumn{4}{|c|}{ Mulheres } \\
\hline & & $\begin{array}{l}\text { TR } \\
(\%)\end{array}$ & $\begin{array}{l}\text { TIR } \\
(\%)\end{array}$ & $\begin{array}{c}\text { AliqNec } \\
(\%)\end{array}$ & $\begin{array}{l}\text { Valor } \\
\text { (R\$) }\end{array}$ & $\begin{array}{l}\text { TR } \\
(\%)\end{array}$ & $\begin{array}{l}\text { TIR } \\
(\%)\end{array}$ & $\begin{array}{c}\text { AliqNec } \\
(\%)\end{array}$ & $\begin{array}{l}\text { Valor } \\
\text { (R\$) }\end{array}$ \\
\hline 25 & 1 & 63,42 & 3,39 & 37,28 & 937 & 79,96 & 4,51 & 47,01 & 1181 \\
\hline \multirow{2}{*}{40} & 3 & 58,18 & 2,48 & 34,21 & 2579 & 79,96 & 4,02 & 47,01 & 3544 \\
\hline & 5 & 51,36 & 2,03 & 30,19 & 3794 & 70,58 & 3,56 & 41,50 & 5214 \\
\hline 30 & 1 & 77,74 & 3,32 & 38,09 & 1268 & 80,62 & 3,48 & 39,50 & 1315 \\
\hline \multirow{2}{*}{35} & 3 & 77,74 & 2,89 & 38,09 & 3805 & 80,62 & 3,05 & 39,50 & 3945 \\
\hline & 5 & 64,76 & 2,30 & 31,73 & 5282 & 67,15 & 2,45 & 32,90 & 5477 \\
\hline 35 & 1 & 78,22 & 2,60 & 32,85 & 1409 & 90,18 & 3,15 & 37,87 & 1624 \\
\hline \multirow[b]{2}{*}{30} & 3 & 78,22 & 2,23 & 32,85 & 4227 & 90,18 & 2,78 & 37,87 & 4873 \\
\hline & 5 & 61,34 & 1,51 & 25,76 & 5524 & 61,42 & 1,52 & 25,79 & 5531 \\
\hline 40 & 1 & 87,41 & 2,46 & 32,12 & 1738 & 99,20 & 2,90 & 36,45 & 1973 \\
\hline \multirow{2}{*}{25} & 3 & 86,76 & 2,11 & 31,88 & 5176 & 92,72 & 2,34 & 34,07 & 5531 \\
\hline & 5 & 55,63 & 0,78 & 20,44 & 5531 & 55,63 & 0,78 & 20,44 & 5531 \\
\hline 45 & 1 & 96,10 & 2,33 & 31,39 & 2110 & 107,70 & 2,71 & 35,18 & 2365 \\
\hline \multirow[b]{2}{*}{20} & 3 & 83,98 & 1,62 & 27,43 & 5531 & 83,98 & 1,62 & 27,43 & 5531 \\
\hline & 5 & 50,39 & 0,19 & 16,46 & 5531 & 50,39 & 0,19 & 16,46 & 5531 \\
\hline 49 & 1 & 102,78 & 2,26 & 30,86 & 2445 & 114,34 & 2,58 & 34,30 & 2717 \\
\hline \multirow{2}{*}{16} & 3 & 77,58 & 1,15 & 23,27 & 5531 & 77,58 & 1,15 & 23,27 & 5531 \\
\hline & 5 & 46,55 & $-0,21$ & 13,96 & 5531 & 46,55 & $-0,21$ & 13,96 & 5531 \\
\hline
\end{tabular}


período contributivo na regra nova (49 anos) com aqueles obtidos com a Regra 85/95. Conforme os dados mostram, quanto mais baixa é a renda inicial, maiores serão as perdas sofridas com a mudança proposta.

Cabe ainda mencionar que é muito improvável que qualquer trabalhador consiga se aposentar pelo teto do RGPS. Isso só será possível com um perfil de renda muito flat, com valor inicial alto, aliado a um período contributivo muito grande.

\subsection{A situação intermediária: a regra de transição da PEC 287}

As Tabelas 7 e 8 apresentam os indicadores para diferentes combinações de período contributivo e idade inicial de contribuição. Embora a PEC 287 elimine as diferenças entre gêneros, os valores são apresentados separadamente para homens e mulheres, para permitir a comparação com os resultados reportados nas Tabelas 1 a 4 . O primeiro ponto a ser destacado é uma queda geral em todos os indicadores, o que evidencia o rigor da reforma proposta. Note-se que com a nova regra, há pouca diferenciação nas Taxas de Reposição (pouco superiores a $60 \%$ em média) quando se aumenta o período contributivo, diferentemente do que ocorre hoje com as ATCs na regra do Fator Previdenciário, na Regra 85/95. A progressividade no tocante à renda também cai. Essas duas características, aliadas ao fim da diferenciação por gênero, permitem afirmar que a PEC 287 reduzirá sobremaneira as características distributivas do sistema previdenciário. Este é um resultado similar àquele apresentado por Palmer (2000) para a reforma feita na Suécia no final do século passado. As mulheres serão as mais afetadas, tendo em vista que todos os seus indicadores são, com a situação anterior à PEC 287, mais elevados que os dos homens.

As Tabelas 7 e 8 apresentam os indicadores para as coortes mais novas, enquadradas na regra de transição: homens(mulheres) com 50(45) anos na data da promulgação da PEC, para a ATC, já incorporando a Regra 85/956. Cada conjunto de resultados traz a situação original e o valor resultante do acréscimo de $50 \%$ no período contributivo. Exemplo: a primeira célula da Tabela 7 apresenta os valores para um trabalhador de 50 anos, que começou a contribuir aos 17, já havia contribuído por 33 anos e esperava contribuir por 35 anos para obter a ATC. Logo, faltavam dois anos para se aposentar. Mas com o acréscimo requerido no período de contribuição, terá que trabalhar $2+1=3$ anos. Com isso seu período contributivo será de 36 anos. O mesmo raciocínio se aplica às demais células e às demais tabelas ${ }^{7}$. Note-se também que no período de transição, além do acréscimo no período contributivo, a aposentadoria já é calculada pela regra da PEC 287.

Deve ser destacado que nem todos os indivíduos terão perdas com o processo de transição. Conforme mostra a Tabela 7, todos os homens que iniciaram sua vida laboral até os 23 anos terão indicadores mais elevados do que na regra original. O motivo deste surpreendente resultado é que este grupo não conseguirá atender aos requisitos da Regra 85/95, o que faz com que haja incidência do fator (com valores reduzidos) sobre sua aposentadoria. Já os homens que começaram a trabalhar a partir dos 25 aposentam-se mais tarde, com o benefício calculado pela Regra 85/95. Note-se ainda que com a regra

\footnotetext{
${ }^{6}$ Para as gerações mais novas não há regra de transição. Todos serão enquadrados nas novas regras.

${ }^{7} \mathrm{~A}$ idade inicial e o período contributivo foram escolhidos de forma a não gerar números não-inteiros no período de transição.
} 
de transição há relativa estabilidade dos indicadores, particularmente da $T R$. Para as mulheres, as conclusões são análogas, com ganhos na situação original para todas que iniciaram suas contribuições até os 23 anos de idade. Porém, como seus indicadores neste caso são maiores que os dos homens, suas perdas com a regra de transição são um pouco mais elevadas. Portanto, os resultados permitem concluir que a fórmula de transição adotada, além de premiar as pessoas que iniciaram sua vida ativa mais cedo (e mantiveram-se como contribuintes o tempo todo), pune aquelas que contribuíram por períodos menores, seja porque trabalharam no setor informal ou porque começaram a trabalhar no setor formal mais tarde.

Se for feita a suposição que este grupo deve ser formado justamente por indivíduos de renda mais elevada, então a reforma tem impactos distributivos, por afetar de modo distinto indivíduos com características diferentes.

Tabela 7: Indicadores previdenciários - Homens - Situação original x Regra de Transição - ATC (com Regra 85/95)

\begin{tabular}{|c|c|c|c|c|c|c|c|c|c|c|}
\hline \multirow{2}{*}{$\begin{array}{c}\text { Renda } \\
\text { inicial } \\
\text { (SM) }\end{array}$} & \multirow{2}{*}{$\begin{array}{c}\text { TC } \\
\text { (anos) }\end{array}$} & \multicolumn{4}{|c|}{ Situação original } & \multirow{2}{*}{$\begin{array}{l}\text { TC } \\
\text { (anos) }\end{array}$} & \multicolumn{4}{|c|}{ Regra de transição } \\
\hline & & $\begin{array}{l}\text { TR } \\
(\%)\end{array}$ & $\begin{array}{l}\text { TIR } \\
(\%)\end{array}$ & $\begin{array}{c}\text { AliqNec } \\
(\%)\end{array}$ & $\begin{array}{l}\text { Valor } \\
\text { (R\$) }\end{array}$ & & $\begin{array}{l}\text { TR } \\
(\%)\end{array}$ & $\begin{array}{l}\text { TIR } \\
(\%)\end{array}$ & $\begin{array}{c}\text { AliqNec } \\
(\%)\end{array}$ & $\begin{array}{l}\text { Valor } \\
\text { (R\$) }\end{array}$ \\
\hline 1 & 35 & 52,02 & 2,33 & 31,01 & 937 & 36 & 62,83 & 2,92 & 37,14 & 1177 \\
\hline 3 & 17 & 46,77 & 1,64 & 27,88 & 2527 & 17 & 62,79 & 2,60 & 37,12 & 3530 \\
\hline 5 & 17 & 36,68 & 1,04 & 21,86 & 3303 & 17 & 50,31 & 2,07 & 29,74 & 4714 \\
\hline 1 & 35 & $\overline{52,02}$ & 2,24 & 30,17 & 937 & 37 & $\overline{63,00}$ & 2,56 & 33,24 & 1204 \\
\hline 3 & 19 & 50,25 & 1,79 & 29,14 & 2715 & 19 & 62,88 & 2.23 & 33,18 & 3606 \\
\hline 5 & 19 & 39,40 & 1,17 & 22,85 & 3548 & 19 & 49,92 & 1,67 & 26,34 & 4770 \\
\hline 1 & 35 & $\overline{54,10}$ & 2,17 & 29,59 & 974 & 38 & 63,17 & 2,26 & 30,41 & 1231 \\
\hline 3 & 21 & 54,10 & 1,84 & 29,59 & 2923 & 21 & 62,92 & 1,92 & 30,29 & 3680 \\
\hline 5 & 21 & 42,43 & 1,20 & 23,20 & 3821 & 21 & 49,52 & 1,34 & 28,34 & 4827 \\
\hline 1 & 35 & $\overline{58,41}$ & 2,34 & 30,95 & 1052 & 39 & 63,32 & 1,92 & 27,62 & 1259 \\
\hline 3 & & 58,41 & 1,99 & 30,95 & 3156 & & 62,92 & 1,58 & 27,44 & 3754 \\
\hline 5 & 23 & 45,80 & 1,35 & 24,27 & 4125 & 23 & 49,12 & 0,97 & 21,43 & 4884 \\
\hline 1 & 35 & $\overline{75,43}$ & 3,03 & 37,31 & 1359 & 40 & 63,48 & 1,37 & 23,79 & 1288 \\
\hline 3 & 25 & 75,43 & 2,68 & 37,31 & 4076 & 25 & 62,88 & 1,01 & 23,57 & 3826 \\
\hline 5 & 20 & 59,15 & 2,01 & 29,26 & 5327 & 20 & 48,72 & 0,37 & 18,26 & 4941 \\
\hline 1 & 35 & $\overline{75,43}$ & 2,91 & 35,94 & 1359 & 41 & 63,63 & 0,90 & 21,07 & 1316 \\
\hline 3 & & 75,43 & 2,55 & 35,94 & 4076 & & 62,80 & 0,53 & 20,80 & 3898 \\
\hline 5 & 27 & 59,15 & 1,87 & 28,19 & 5327 & 27 & 48,31 & $-0,15$ & 16,00 & 4997 \\
\hline
\end{tabular}

Seguindo o mesmo padrão, as Tabelas 9 e 10 trazem os resultados da transição para a aposentadoria por idade, respectivamente, para homens e mulheres $^{8}$. Nos dois casos, as perdas não são tão grandes quanto no caso das ATCs, pois hoje a idade mínima para obter a AI já é 65(60) anos, implicando menor esforço contributivo adicional exigido para as coortes em questão. Esta é uma caraterística positiva desta regra de transição, pois penaliza menos os indivíduos de renda mais baixa, que se aposentam por idade (desde que mantenham sua condição de contribuintes). Finalmente, cabe notar que, com a regra de transição, as TIRs chegam a ser negativas para os homens que precisarão trabalhar mais, pois o período de recebimento do benefício passa a ser bastante reduzido.

\footnotetext{
${ }^{8}$ A notação NC significa que não foi possível calcular a aposentadoria, pois esta seria concedida com idade superior a 80 anos e a tábua de mortalidade do IBGE tem como última referência os indivíduos com $80+$ anos.
} 
Tabela 8: Indicadores previdenciários - Mulheres - Situação original x Regra de Transição - ATC (com Regra 85/95)

\begin{tabular}{|c|c|c|c|c|c|c|c|c|c|c|}
\hline \multirow{2}{*}{$\begin{array}{c}\text { Renda } \\
\text { inicial } \\
(S M)\end{array}$} & \multirow{2}{*}{\begin{tabular}{|c} 
TC \\
(anos)
\end{tabular}} & \multicolumn{4}{|c|}{ Situação original } & \multirow{2}{*}{\begin{tabular}{|l} 
TC \\
(anos)
\end{tabular}} & \multicolumn{4}{|c|}{ Regra de transição } \\
\hline & & $\begin{array}{l}\text { TR } \\
(\%)\end{array}$ & $\begin{array}{l}\text { TIR } \\
(\%)\end{array}$ & $\begin{array}{c}\text { AliqNec } \\
(\%)\end{array}$ & $\begin{array}{l}\text { Valor } \\
\text { (R\$) }\end{array}$ & & $\begin{array}{l}\text { TR } \\
(\%)\end{array}$ & $\begin{array}{l}\text { TIR } \\
(\%)\end{array}$ & $\begin{array}{c}\text { AliqNec } \\
(\%)\end{array}$ & $\begin{array}{l}\text { Valor } \\
\text { (R\$) }\end{array}$ \\
\hline 1 & 30 & 57,44 & 3,65 & 45,03 & 937 & 31 & 61,89 & 3,77 & 46,85 & 1050 \\
\hline 3 & & 40,68 & 2,10 & 31,89 & 1991 & & 61,89 & 3,42 & 46,85 & 3151 \\
\hline 5 & 17 & 33,88 & 1,64 & 25,56 & 2764 & 17 & 52,18 & 2,99 & 39,50 & 4428 \\
\hline 1 & 30 & 57,44 & 3,53 & 45,06 & 937 & 32 & 62,09 & 3,45 & 42,38 & 1075 \\
\hline 3 & & 43,47 & 2,18 & 32,59 & 2127 & & 62,09 & 3,1 & 42,38 & 3225 \\
\hline 5 & 19 & 36,21 & 1,70 & 27,14 & 2954 & 19 & 51,82 & 2,64 & 35,37 & 4485 \\
\hline 1 & 30 & 57,44 & 3,39 & 41,00 & 937 & 33 & 62,28 & 3,17 & 39,08 & 1100 \\
\hline 3 & & 46,55 & 2,25 & 33,23 & 2278 & 2 & 62,28 & 2,82 & 39,08 & 3299 \\
\hline 5 & 21 & 38,77 & 1,76 & 27,68 & 3163 & 21 & 51,45 & 2,33 & 32,28 & 4542 \\
\hline 1 & 30 & 57,44 & 3,31 & 39,95 & 937 & 34 & 62,47 & 2,77 & 34,75 & 1125 \\
\hline 3 & & 49,95 & 2,42 & 34,74 & 2444 & & 62,47 & 2,41 & 34,75 & 3376 \\
\hline 5 & 23 & 41,61 & 1,92 & 28,94 & 3394 & 23 & 51,07 & 1,89 & 28,41 & 4600 \\
\hline 1 & 30 & 77,74 & 4,29 & 51,12 & 1268 & 35 & 62,65 & 2,42 & 31,61 & 1151 \\
\hline 3 & ? & 77,74 & 3,90 & 51,12 & 3805 & ? & 62,65 & 2,07 & 31,61 & 3453 \\
\hline 5 & 25 & 64,76 & 3,37 & 42,58 & 5282 & 25 & 50,69 & 1,52 & 25,58 & 4657 \\
\hline 1 & 30 & 77,74 & 4,11 & 48,05 & 1268 & 36 & 62,83 & 2,05 & 28,54 & 1177 \\
\hline 3 & 27 & 77,74 & 3,72 & 48,05 & 3805 & ?ר & 62,79 & 1,69 & 28,52 & 3530 \\
\hline 5 & 27 & 64,76 & 3,17 & 40,03 & 5282 & 27 & 50,31 & 1,11 & 22,85 & 4714 \\
\hline
\end{tabular}

Tabela 9: Indicadores previdenciários - Homens - Situação original x Transição - AI

\begin{tabular}{|c|c|c|c|c|c|c|c|c|c|c|}
\hline \multirow{2}{*}{$\begin{array}{c}\text { Renda } \\
\text { inicial } \\
(\mathrm{SM})\end{array}$} & \multirow{2}{*}{\begin{tabular}{|c} 
TC \\
(anos)
\end{tabular}} & \multicolumn{4}{|c|}{ Situação original } & \multirow{2}{*}{\begin{tabular}{|c} 
TC \\
(anos)
\end{tabular}} & \multicolumn{4}{|c|}{ Regra de transição } \\
\hline & & $\begin{array}{l}\text { TR } \\
(\%)\end{array}$ & $\begin{array}{l}\text { TIR } \\
(\%)\end{array}$ & $\begin{array}{c}\text { AliqNec } \\
(\%)\end{array}$ & $\begin{array}{l}\text { Valor } \\
\text { (R\$) }\end{array}$ & & $\begin{array}{l}\text { TR } \\
(\%)\end{array}$ & $\begin{array}{l}\text { TIR } \\
(\%)\end{array}$ & $\begin{array}{c}\text { AliqNec } \\
(\%)\end{array}$ & $\begin{array}{l}\text { Valor } \\
\text { (R\$) }\end{array}$ \\
\hline 1 & 15 & |77,30 & 8,66 & 75,75 & 937 & 16 & |74,30 & 7,67 & 66,37 & 937 \\
\hline 3 & & 70,71 & 7,34 & 69,29 & 2571 & & 57,99 & 5,33 & 51,80 & 2194 \\
\hline 5 & 31 & 68,98 & 7,21 & 67,59 & 4181 & 31 & 56,06 & 5,16 & 50,08 & 3535 \\
\hline 1 & 15 & 77,30 & 8,27 & 68,60 & 937 & 17 & 72,84 & 6,47 & 55,06 & 937 \\
\hline 3 & 53 & 70,71 & 6,90 & 62,75 & 2571 & 53 & 58,31 & 4,31 & 44,07 & 2250 \\
\hline 5 & & 68,98 & 6,77 & 61,21 & 4181 & 30 & 55,94 & 4,11 & 42,28 & 3598 \\
\hline 1 & 15 & 77,30 & 8,03 & 64,92 & 937 & 18 & 71,42 & 5,19 & 45,03 & 937 \\
\hline 3 & 55 & 70,71 & 6,63 & 59,38 & 2571 & 55 & 58,62 & 3,18 & 36,96 & 2307 \\
\hline 5 & 30 & 68,98 & 6,50 & 57,93 & 4181 & 30 & 55,79 & 2,95 & 35,18 & 3660 \\
\hline 1 & 15 & 77,30 & 7,75 & 61,17 & 937 & 19 & 70,02 & 3,74 & 36,07 & 937 \\
\hline 3 & 57 & 70,71 & 6,32 & 55,95 & 2571 & 57 & 58,92 & 1,85 & 30,35 & 2365 \\
\hline 5 & נו & 68,98 & 6,19 & 54,58 & 4181 & נו & 55,62 & 1,58 & 28,65 & 3722 \\
\hline 1 & 15 & 77,30 & 7,42 & 57,34 & 937 & 20 & 68,64 & 2,66 & 30,83 & 937 \\
\hline 3 & 59 & 70,71 & 5,96 & 54,25 & 2571 & 50 & 59,21 & 0,94 & 26,59 & 2425 \\
\hline 5 & על & 68,98 & 5,82 & 51,16 & 4181 & בני & 55,42 & 0,64 & 24,89 & 3782 \\
\hline
\end{tabular}


Tabela 10: Indicadores previdenciários - Mulheres - Situação original x Transição - AI

\begin{tabular}{|c|c|c|c|c|c|c|c|c|c|c|}
\hline \multirow{2}{*}{$\begin{array}{c}\text { Renda } \\
\text { inicial } \\
(\mathrm{SM})\end{array}$} & \multirow{2}{*}{ 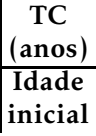 } & \multicolumn{4}{|c|}{ Situação original } & \multirow{2}{*}{\begin{tabular}{|c} 
TC \\
(anos)
\end{tabular}} & \multicolumn{4}{|c|}{ Regra de transição } \\
\hline & & $\begin{array}{l}\text { TR } \\
(\%)\end{array}$ & $\begin{array}{l}\text { TIR } \\
(\%)\end{array}$ & $\begin{array}{c}\text { AliqNec } \\
(\%)\end{array}$ & $\begin{array}{l}\text { Valor } \\
\text { (R\$) }\end{array}$ & & $\begin{array}{l}\text { TR } \\
(\%)\end{array}$ & $\begin{array}{l}\text { TIR } \\
(\%)\end{array}$ & $\begin{array}{c}\text { AliqNec } \\
(\%)\end{array}$ & $\begin{array}{l}\text { Valor } \\
\text { (R\$) }\end{array}$ \\
\hline 1 & 16 & 77,3 & 9,08 & 85,95 & 937 & 15 & |74,30 & 8,28 & 79,00 & 937 \\
\hline 3 & & 70,71 & 7,81 & 78,62 & 2194 & & 57,99 & 6,09 & 61,66 & 2571 \\
\hline 5 & 40 & 68,98 & 7,68 & 76,69 & 3535 & 40 & 56,06 & 5,93 & 59,61 & 4181 \\
\hline 1 & 17 & 777,30 & 8,96 & 82,62 & 937 & 15 & $\overline{72,84}$ & 7,13 & 64,25 & 937 \\
\hline 3 & 48 & 70,71 & 7,67 & 75,57 & 2250 & 18 & 58,31 & 5,10 & 51,42 & 2571 \\
\hline 5 & 48 & 68,98 & 7,55 & 73,72 & 3598 & 48 & 55,94 & 4,91 & 49,34 & 4181 \\
\hline 1 & 18 & 777,30 & 8,66 & 75,75 & 937 & 15 & $\overline{71,42}$ & 6,08 & 53,87 & 937 \\
\hline 3 & 50 & 70,71 & 7,34 & 69,29 & 2307 & 50 & 58,62 & 4,20 & 44,22 & 2571 \\
\hline 5 & 30 & 68,98 & 7,21 & 67,59 & 3660 & 50 & 55,79 & 3,98 & 42,09 & 4181 \\
\hline 1 & 19 & 77,30 & 8,48 & 72,21 & 937 & 15 & 70,02 & 4,94 & 44,61 & 937 \\
\hline 3 & 52 & 70,71 & 7,13 & 66,05 & 2365 & 50 & 58,92 & 3,21 & 37,54 & 2571 \\
\hline 5 & 32 & 68,98 & 7,00 & 64,43 & 3722 & 32 & 55,62 & 2,95 & 35,44 & 4181 \\
\hline 1 & 20 & 77,30 & 8,27 & 68,60 & 937 & 15 & 68,64 & 4,07 & 38,95 & 937 \\
\hline 3 & 54 & 70,71 & 6,9 & 62,75 & 2425 & 54 & 59,21 & 2,51 & 33,60 & 2571 \\
\hline 5 & 4 & 68,98 & 6,77 & 61,21 & 3782 & 4 & 55,42 & 2,22 & 31,44 & 4181 \\
\hline 1 & 21 & 77,30 & 7,75 & 61,17 & 937 & 15 & 67,30 & 2,73 & 31,36 & 937 \\
\hline 3 & 56 & 70,71 & 6,32 & 55,95 & 2485 & 56 & 59,49 & 1,28 & 27,73 & 2571 \\
\hline 5 & 30 & 68,98 & 6,19 & 54,58 & 3843 & 50 & 55,20 & 0,95 & 25,72 & 4181 \\
\hline
\end{tabular}

\section{Conclusões}

Este trabalho teve por objetivo fazer uma avaliação dos aspectos distributivos da PEC 287, caso ela viesse a ser aprovada sem modificações em relação ao texto proposto pelo governo em dezembro de 2016. Para isto foi utilizada a metodologia dos indivíduos representativos, com diferentes perfis de gênero, renda inicial, período contributivo e idade inicial de contribuição. Foram calculados três indicadores previdenciários de uso padrão na literatura: Taxa de Reposição (TR), Taxa Interna de Retorno (TIR) e Alíquota Necessária (Aliq$\mathrm{Nec}$ ), bem como foram computados os valores dos dois benefícios programáveis mais relevantes do RGPS, aposentadoria por tempo de contribuição (ATC) e aposentadoria por idade (AI). Os valores foram estimados para três casos: a situação anterior à reforma (tanto para a incidência do Fator Previdenciário, quanto para a Regra 85/95, quando esta for aplicável); para a regra nova, da PEC 287; e para o período de transição.

É possível concluir que na situação inicial, no tocante aos benefícios analisados, o RGPS tem características distributivas, pois os indicadores são, via de regra, superiores para as mulheres, para trabalhadores de renda mais baixa e para aqueles que se aposentam por idade. Ainda que esta progressividade seja uma característica defensável, parcela esmagadora dos valores encontrados encontra-se muito acima daqueles reportados na literatura internacional. Como há um subsídio implícito à maior parte dos beneficiários, o resultado da agregação desta generosidade em termos individuais é um déficit fiscal expressivo e crescente, dado o processo de envelhecimento da população pelo qual passa o Brasil. Este quadro foi agravado pela Regra 85/95, que incrementou enormemente os benefícios para aqueles que atingissem a soma mínima de anos de contribuição e idade. Houve duas consequências imediatas: a primeira foi a geração de descontinuidades nos indicadores, pois a fórmula de 
cálculo do benefício muda abruptamente para os que atingem o requisito da regra. A segunda, decorrente da primeira, foi a virtual eliminação dos princípios de neutralidade atuarial que o sistema pudesse ter.

Há redução em todos os indicadores calculados para as regras dadas nesta proposição de reforma. Como o objetivo do governo é, no mínimo, estabilizar o déficit previdenciário, estes achados fornecem evidências de que as medidas estão na direção correta, apesar de não serem neutras. Haverá um rearranjo distributivo intrageracional. Mulheres, aqueles(as) que se aposentam por idade e trabalhadores(as) de baixa renda serão os mais afetados. $\mathrm{O}$ sistema perderá parcela expressiva de suas características distributivas. Cabe interpretar este resultado com cautela. A proposta inicial de reforma está alinhada com as mudanças feitas em vários países (Börsch-Supan et al. 2007, Holzmann \& Guven 2009, Mesa-Lago \& Bertranou 2016). Princípios de universalização e eliminação de diferenças embasam as medidas. É esperado que os grupos mais beneficiados pelo atual desenho sejam os que irão sofrer as maiores reduções nos seus indicadores. Será muito pouco provável alcançar o valor máximo dos benefícios. Pode-se interpretar que o governo encontrou uma forma de reduzir o teto, sem fazê-lo de forma explícita. Igualmente é possível afirmar que para o maior período contributivo (49 anos) as maiores perdas estão concentradas sobre os trabalhadores de renda baixa, devido ao novo sistema apresentar maiores neutralidade e justiça atuariais, bem como reduzidas características distributivas.

Os resultados fornecem evidências de que a regra de transição produzirá efeitos distintos sobre indivíduos de perfis diferentes, em particular aqueles que se aposentam por tempo de contribuição. Por este motivo, é natural esperar que estes oponham maior resistência às mudanças, o que já estava ocorrendo no momento em que este texto era finalizado. Deve-se mencionar ainda que a PEC 287 só prevê uma regra de transição para aqueles(as) com idade igual ou superior a 50(45) anos. Para os demais há o enquadramento imediato na nova regra.

Concluindo, é possível afirmar que a PEC 287, nos termos originais, tem medidas duras, porém necessárias e bem embasadas, dado o desequilíbrio das contas previdenciárias. Mas sua implantação produzirá, conforme evidenciado pelos resultados, impactos redistributivos aos quais não têm sido dado o devido destaque. Este trabalho sugere primeiramente a necessidade de estudos adicionais para calcular a magnitude dos impactos fiscais e da redução de gastos que a adoção desta reforma produzirá. Em segundo lugar, as evidências de que a implantação das medidas propostas reduzirá o caráter redistributivo do RGPS sugerem a necessidade de considerar a adoção de medidas adicionais para distribuir os custos da transição aos grupos não atingidos pela proposição de reforma feita pelo governo Temer em 2016.

\section{Referências Bibliográficas}

Adascalitei, D. \& Domonkos, S. (2015), 'Reforming against all odds: Multipillar pension systems in the Czech Republic and Romania', International Social Security Review 68(2), 85-104.

Afonso, L. E. (2016), 'Progressividade e aspectos distributivos na previdência social: Uma análise com o emprego dos microdados dos registros administrativos do RGPS', Revista Brasileira de Economia 70(1), 3-30. 
Auerbach, A. J. \& Lee, R. (2011), 'Welfare and Generational Equity in Sustainable Unfunded Pension Systems', Journal of Public Economics 95(1-2), 1627.

Barr, N. \& Diamond, P. (2006), 'The Economics of Pensions', Oxford Review of Economic Policy 22(1), 15-39.

Biggs, A. G., Sarney, M. \& Tamborini, C. R. (2009), A progressivity index for Social Security. Issue Paper No. 2009-1.

URL: $h t t p: / / w w w . s s a . g o v / p o l i c y / d o c s / i s s u e p a p e r s / i p 2009-01 . p d f$

Boado-Penas, M. C., Valdés-Prieto, S. \& Vidal-Meliá, C. (2008), 'The Actuarial Balance Sheet for Pay-As-You-Go Finance: Solvency Indicators for Spain and Sweden', Fiscal Studies 29(1), 89-134.

Breyer, F. \& Hupfeld, S. (2010), 'On the Fairness of Early-Retirement Provisions', German Economic Review 11(1), 60-77.

Börsch-Supan, A., Kohnz, S. \& Schnabel, R. (2007), 'The Budget Impact of Reduced Early Retirement Incentives on the German Public Pension System', in J. Gruber \& D. A. Wise, eds, 'Social Security Programs and Retirement around the World: Fiscal Implications of Reform', 1 ed, Chicago: University of Chicago Press, pp. 201-252.

Caetano, M. A. R. (2006), Subsídios cruzados na previdência social brasileira. Texto para Discussão - Brasília: IPEA.

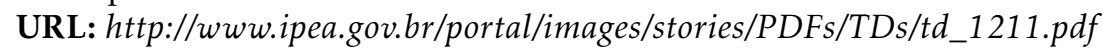

Coronado, J. L., Fullerton, D. \& Glass, T. (2002), 'Long-Run Effects of Social Security Reform Proposals on Lifetime Progressivity', in M. Feldstein \& J. B. Liebman, eds, 'The Distributional Aspects of Social Security and Social Security Reform', Chicago: University of Chicago Press, pp. 149-205.

Devolder, P. (2015), 'Pension Reform in Belgium: a new points system between DB and DC', in R. Norberg, ed., 'Proceedings of Colloquium of the International Actuarial Association - LIFE/PBSS/IACA', Oslo: International Actuarial Association (IAA). Pensions and Benefits Section, pp. 1-20.

Díaz-Giménez, J. \& Díaz-Saavedra, J. (2016), 'The future of Spanish pensions', Journal of Pension Economics and Finance 1, 1-33.

Favreault, M. M., Steuerle, C. E. et al. (2012), Social Measuring Social Security Proposals by More than Solvency: Impacts on Poverty, Progressivity, Horizontal Equity, and Work Incentives, Technical report, Boston: Boston College. (Center for Retirement Research - Technical Report).

Feldstein, M. \& Liebman, J. B. (2002), 'In A. J. Auerbach \& M. Feldstein (Eds.)', Handbook of Public Economics vol. 4, 2245-2324.

Forteza, A. (2015), 'Are social security programs progressive?', IZA World of Labor pp. 1-10.

Giambiagi, F. \& Afonso, L. E. (2009), 'Cálculo da alíquota de contribuição previdenciária atuarialmente equilibrada: uma aplicação ao caso brasileiro', Revista Brasileira de Economia 63(2), 153-179. 
Guillemard, A. M. (1999), 'Equity and redistribution between generations: a challenge for the future of pensions and all social protection schemes', International Social Security Review 52(3), 69-92.

Gustman, A. L., Steinmeier, T. L. \& Tabatabai, N. (2012), 'Redistribution under the Social Security benefit formula at the individual and household levels, 1992 and 2004', Journal of Pension Economics E Finance 12(1), 1-27.

Hernæs, E., Markussen, S., Piggott, J. \& Røed, K. (2016), 'Pension reform and labor supply', Journal of Public Economics 142, 39-55.

Holzmann, R. \& Guven, U. (2009), Adequacy of Retirement Income after Pension Reforms in Central, Eastern, and Southern Europe Eight Country Studies, Washington, D.C.: World Bank.

Lindbeck, A. (2006), 'Conceptualization of Non-Financial Defined Contribution Systems', in R. Holzmann \& E. Palmer, eds, 'Pension Reform: Issues and Prospects for Non-Financial Defined Contribution (NDC) Schemes', Vol. 1, Washington, D.C.: World Bank, pp. 71-75.

Mattil, B. (2006), 'Objectives of pension systems', in Pension Systems: Sustainability and Distributional Effects in Germany and the United Kingdom . Heidelberg: Physica-Verlag, p. 7-26.

Meneu, R., Devesa, E., Devesa, M., Domínguez, I. \& Encinas, B. (2016), 'Adjustment mechanisms and intergenerational actuarial neutrality in pension reforms', International Social Security Review 69(1), 87-107.

Merriam, I. C. (1977), 'The Objectives of Social Security Research and Evaluation', International Social Work 20(1), 2-14.

Mesa-Lago, C. \& Bertranou, F. (2016), 'Pension reforms in Chile and social security principles, 1981-2015', International Social Security Review 69(1), 2545 .

OECD (2014), Pensions at a Glance: Latin America and the Caribbean. Paris: OCDE.

OECD (2015), Pensions at a Glance 2015: OECD and G20 indicators. Paris: OECD.

Olivera, J. (2016), 'Welfare, inequality and financial effects of a multipillar pension reform: The case of Peru', The Journal of Development Studies 52(10), 1401-1414.

Pallares-Miralles, M., Romero, C. \& Whitehouse, E. (2012), International Patterns of Pension Provision II: A Worldwide Overview of Facts and Figures. Social Protection \& Labor Discussion Paper No. 1211. Washington, D.C.: World Bank.

URL: http://www-wds.worldbank.org/external/default/WDSContentServer/ WDSP/IB/2012/06/21/000333038_20120621024626/Rendered/PDF/703190 NWP0SPL000Box370035B00PUBLIC0.pdf

Palmer, E. (2000), The Swedish Pension Reform Model: framework and issues. Social Protection Discussion Paper (Vol. 23086). Washington, D.C. 
Penafieri, A. C. \& Afonso, L. E. (2013), 'O impacto da mudança da regra de cálculo das aposentadorias por tempo de contribuição do INSS: o fator previdenciário é atuarialmente justo?', Economia Aplicada 17(4), 667-694.

Presidência da República (2016), Proposta de Emenda à Constituição (PEC) 287. Brasília, Brasília. Casa Civil. Subchefia para Assuntos Jurídicos.

URL: Retrieved from http://www.camara.gov.br/proposicoesWeb/prop_mos trarintegra;jsessionid $=6$ D0F4104EC5F2309A5E239BB49C61F6B.proposicoes WebExterno1?

Purcell, P. J. (2012), 'Income replacement ratios in the Health and Retirement Study', Soc. Sec. Bull. 72, 37.

Schmähl, W. (1999), 'Fundamental decisions for the reform of pension systems', International Social Security Review 52(3), 45-55.

Schröder, C. (2012), 'Profitability of pension contributions-evidence from real-life employment biographies', Journal of Pension Economics E Finance 11(3), 311-336.

Schwarz, A. M. \& Abels, M. (2016), Issues for Civil Service Pension Reform in Sub-Saharan Africa. Social Protection \& Labor Discussion Paper No. 161. Washington, D.C.

URL: http://elibrary.worldbank.org/doi/abs/10.1596/25364

Stepan, M. \& Anderson, K. M. (2014), 'Pension reform in the European periphery: the role of EU reform advocacy', Public administration and development 34(4), 320-331.

Symeonidis, G. (2016), The Greek Pension Reform Strategy: 2010-2015. Social Protection \& Labor Discussion Paper. Washington, D.C.: World Bank.

URL: http://documents.worldbank.org/curated/en/2016/05/26395359/greekpension-reform-strategy-20102015

Queisser, Monika and Whitehouse, Edward R and others (2006), Technical report, OECD Publishing.

Turra, C. M. \& Afonso, L. E. (2017), 'A consolidação da Previdência Social desde 1988 e seu futuro em um país em envelhecimento', in P. de T. A. Paiva \& G. F. Mendes, eds, 'Politicas públicas no Brasil: suas raizes institucionais, sua gestão e seus desafios', São Paulo: Saraiva.

Vidal-Meliá, C., Carmen, B. P. M. \& Settergren, O. (2009), 'Automatic balance mechanisms in pay-as-you-go pension systems', The Geneva Papers on Risk and Insurance-Issues and Practice 34(2), 287-317. 